\title{
Management of digital ulcers in systemic sclerosis
}

This article was published in the following Dove Press journal:

Chronic Wound Care Management and Research

\section{Simone Barsotti \\ Marco Di Battista \\ Valentina Venturini \\ Alessandra Della Rossa \\ Marta Mosca}

Rheumatology Unit, Pisa University Hospital, Pisa, Italy
Correspondence: Simone Barsotti Rheumatology Unit, University of Pisa, Italy, 67 Via Roma, Italy, 56|26, Italy Tel +39050 992246

Email simone.barsotti.pisa@gmail.com

\begin{abstract}
Systemic sclerosis (SSc) is a rare disease characterized by autoimmune pathogenesis, alterations to the vascular system, and fibrosis of the skin and internal organs. Digital ulcers (DUs) are common in SSc patients, and represent a major burden for the patients. The management of DUs in systemic sclerosis is difficult, because it needs a multimodal therapeutic approach, as local treatment alone is usually insufficient and also systemic treatment with vasoactive drugs and modification of the lifestyle are usually required for healing of the wounds. In this review, we describe the optimal management of DUs according to recent literature and our clinical practice for systemic and local treatment of chronic digital wounds in SSc patients.
\end{abstract}

Keywords: systemic sclerosis, wound, digital ulcers, dressings

\section{Introduction}

Systemic sclerosis (SSc) is a rare connective-tissue disease characterized by autoimmune pathogenesis, alterations to the vascular system, and fibrosis of the skin and internal organs. ${ }^{1}$ It is estimated that about $30 \%$ of SSc patients develop digital ulcers (DUs) yearly and up to $50 \%$ of subjects develop this complication during the natural course of the disease., ${ }^{2,3}$ DUs represent a major burden, as they are severely painful, difficult to heal, and lead to substantial functional disability and poor outcomes. Moreover, DUs are often associated with scarring and acroosteolysis and infection, and in severe cases may progress to gangrene, requiring amputation. ${ }^{4}$

The pathogenesis of DUs is complex and strictly related both to the vasoconstriction associated with Raynaud's phenomenon, which reduces tissue oxygenation, ${ }^{5}$ and to skin thickening on the hands, which may increase the risk of microtrauma and local injuries.

DUs may have different aspects in SSc patients (Figure 1), and their pathogenesis may involve several different mechanisms that interfere with one another. For these reasons, treatment of these wounds is complex, requires a global approach to the patient, and includes modification of the patient's lifestyle and pharmacological and nonpharmacological approaches.

The aim of the treatment is on one hand to favor healing of existing DUs and on the other to prevent the appearance of new DUs.

\section{Lifestyle modification}

The incidence of scleroderma DUs, is strictly associated with peripheral oxygenation and the intensity of Raynaud's phenomenon, which may change according to lifestyle modifications. ${ }^{6}$

Avoidance of cold remains one the most effective lifestyle modifications to be suggested to patients, and it is crucial that SSc patients take all possible measures to 


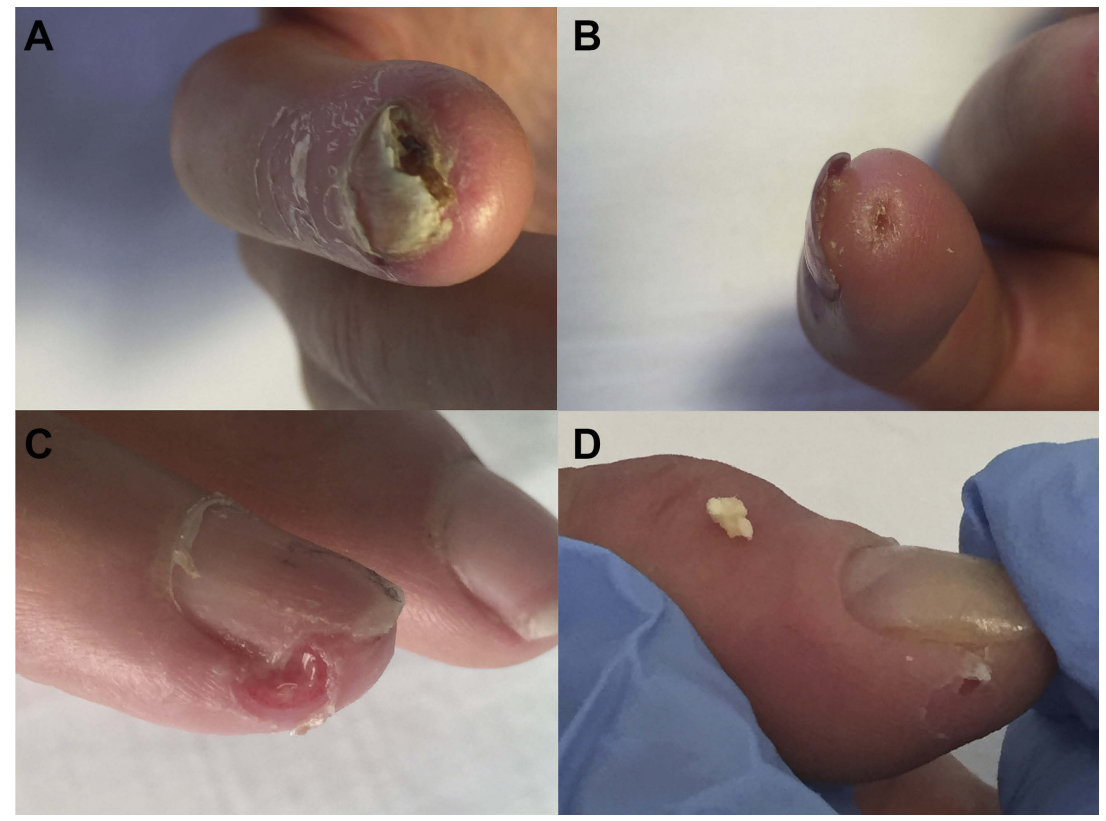

Figure I Different aspects of DUs in patients with SSc.Notes: (A) Subungual wound in a patient with diffuse cutaneous SSc. (B) Digital lesion of the fingertip in a patient with limited cutaneous SSc. (C) Subungual ulcer in a patient with SSc without skin involvement. (D) Digital ulcer due to subcutaneous calcinosis of the fingertip. Removal of the calcium deposit is fundamental for the healing of the wound.

Abbreviations: SSc, systemic sclerosis; DUs, digital ulcers.

avoid or at least minimize exposure to cold. Patients should be advised to wear multiple layers of clothes, wear gloves, rub the hands in warm water, and avoid rapidly shifting temperatures.

Since even a stressful environment can contribute to the worsening of microangiopathy, patients should learn to deal with stress, avoiding stressful situations when possible. It is also important to avoid activities that cause recurrent digital trauma. ${ }^{5}$ Raynaud's phenomenon triggers, such as excessive caffeine intake, should be avoided too. ${ }^{7}$

One of the most important lifestyle modifications that should be suggested strongly to patient is total smoking cessation, as smoking heavily worsens microvascular involvement. In addition, as smoking is associated with a higher risk of DUs, ${ }^{8}$ all available support to aid smoking cessation should be given to patients. ${ }^{9}$ Particular guidance should also be given for personal hygiene, as in many SScrelated DUs fecal pathogens may be isolated. ${ }^{10}$

Although no clear evidence of the effects of medications have been reported in the literature, drugs that promote vasoconstriction and worsen Raynaud's phenomenon, such as $\beta$-blockers, ${ }^{7}$ migraine medications like sumatriptan and ergotamine 6 , and drugs that increase sympathetic nervous system activity like ephedrine, pseudoephedrine, or adrenalin (eg, nasal decongestionants ${ }^{11}$ may have a role in the pathogenesis of SSc DUs and should be stopped if possible.
There is no clear evidence to support the use of complementary forms of therapy, including biofeedback, acupuncture, laser therapy, and herbal agents in the management of Raynaud's phenomenon and DUs in SSc patients. ${ }^{12}$

\section{Systemic therapy}

The systemic approach to the treatment of DUs first requires general measures, such as adequate opiate-based analgesia in the short term, useful also to prevent pain-induced vasoconstriction, ${ }^{13}$ and antibiotics in cases of infection. ${ }^{14}$

The pharmacological treatment of SSc-related DUs is manly based on vasoactive therapies: one drug or combinations (Table 1). Despite different treatments having benn proposed for the treatment of these wounds and to prevent the development of new lesions, no clear indications have been reported in current guidelines for the management of SSc, ${ }^{15,16}$ and therapy should always be tailored according to the characteristics of patients and the disease.

The use of immunosuppressants, commonly prescribed for other internal organ involvement, for the treatment of SSc DUs is still under review. ${ }^{17}$ Although immunosuppressants may have a positive impact on disease activity and consequently on DU improvement, SSc DUs are often infected and a possible increase in infectious risk has to be carefully weighed, as when a severe local infection occurs, 
Table I Vasodilators that may be useful in the treatment of SSc DUs

\begin{tabular}{|c|c|c|}
\hline Class & Main drugs & Pharmacological effect \\
\hline Prostanoids & Iloprost Treprostinil & $\begin{array}{l}\text { Analogues of prostacyclin } \rightarrow \text { dilation of arterioles and venules, inhibition of platelet aggregation, } \\
\text { activation of fibrinolysis, blocking of leukocyte migration, reduction of oxygen-reactive species release }\end{array}$ \\
\hline PDE5 inhibitors & Sildenafil Tadalafil & $\begin{array}{l}\text { Inhibition of PDE5 } \rightarrow \text { inhibition of cyclic guanosine monophosphate degradation } \rightarrow \text { increase of } \\
\text { endogenous nitric oxide levels }\end{array}$ \\
\hline ERAs & Bosentan & $\begin{array}{l}\text { Inhibition of both endothelin I receptors }\left(\mathrm{ET}_{\mathrm{A}} \text { and } \mathrm{ET}_{\mathrm{B}}\right) \rightarrow \text { inhibition of endothelin-mediated vascular } \\
\text { constriction and hyperplasia }\end{array}$ \\
\hline CCBs & Nifedipine Amlodipine & $\begin{array}{l}\text { Prevention or reduction of calcium channels opening } \rightarrow \text { decrease in intracellular calcium } \rightarrow \text { inhibition } \\
\text { of vasoconstriction }\end{array}$ \\
\hline
\end{tabular}

Abbreviations: SSc, systemic sclerosis; DUs, digital ulcers; PDE5, phosphodiesterase; ERA, endothelin-receptor antagonists; CCBs, calcium-channel blockers.

immunosuppressive drugs may be temporarily stopped to promote the healing of the DUs.

\section{Prostanoids}

Prostanoids, stable synthetic analogues of prostacyclin, are potent vasodilators and may interfere with several pathogenic mechanisms of SSc DUs, such as platelet aggregation and vascular smooth muscle-cell proliferation, reducing the release of oxygen-reactive species and the expression of adhesion molecules, activating fibrinolysis, and blocking leukocyte migration. Prostanoids are typically administered intravenously (IV), even if oral administration may be possible.

In the first half of the 1990s, two randomized controlled trials (RCTs) evaluated iloprost IV at the dosage of $0.5-2.0 \mathrm{ng} / \mathrm{kg} / \mathrm{min}$ over 6 hours for 5 days consecutively, and found that it was significantly more efficacious than placebo in healing DUs in SSc patients. For example, in one of these studies, conducted on 126 patients, after 3 weeks of treatment DU healing $\geq 50 \%$ in $14.6 \%$ more patients who received iloprost than placebo was already noticeable. ${ }^{18,19}$

Over the years, several prostanoids have been studied in SSc, sometimes with conflicting results. In a recent RCT on 147 patients, oral treprostinil was associated with small and statistically insignificant reductions in net ulcer burden in comparison to placebo. In addition to the absence of effects on ulcer healing or prevention, there were only small, inconsistent effects on Raynaud's phenomenon, global assessment, hand function, and qualityof-life measures. ${ }^{20} \mathrm{~A}$ retrospective study on 51 patients highlighted instead how the number of DUs, which had decreased during oral treprostinil exposure, was significantly increased in the year after drug withdrawal. ${ }^{21}$

In 2013, a meta-analysis of eleven RCTs on iloprost IV and oral beraprost, cicaprost, iloprost, and treprostinil reconfirmed that prostanoids determine the healing of DUs in SSc, revealing that iloprost IV had the greatest effect. Moreover, iloprost IV also showed efficacy in reduction of onset of new DUs, while oral prostanoids were not associated with a similar preventive effect ${ }^{22}$ Further studies are required to confirm the potential beneficial effect of iloprost IV in DU prevention. However, a recent study in a real-life setting showed that iloprost IV was effective in healing and prevention of SSc DUs over 10 years' follow-up, with satisfactory safety and tolerability. ${ }^{23}$ Unfortunately, iloprost and other prostanoids have a short half-life and pharmacological effect, ${ }^{24}$ and cyclical repetitions of therapy are needed. ${ }^{25}$

On the basis of these results, European League Against Rheumatism (EULAR) guidelines state that iloprost IV (0.5-2 ng $/ \mathrm{kg} / \mathrm{min} 6-8$ hours per day for 3-5 consecutive days) should be considered in the treatment of DUs in SSc patients (strength of recommendation: A) ${ }^{26}$ Regarding dosage, there is evidence that low-dose $(0.5 \mathrm{ng} / \mathrm{kg} / \mathrm{min})$ and high-dose $(2 \mathrm{ng} / \mathrm{kg} / \mathrm{min})$ iloprost have substantially the same effectiveness in long-term treatment. ${ }^{27}$ Multiple studies have shown that administration of a mean iloprost dose of $1 \mathrm{ng} / \mathrm{kg} / \mathrm{min}$ results in well-tolerated therapy without losing clinical efficacy. ${ }^{8,23,25-27}$ As the results of the medical literature are not homogeneous, iloprost administration dose has to be tailored in accordance with the patient's individual tolerability.

Selexipag, an oral selective IP prostacyclin-receptor agonist, has demonstrated positive effects on pulmonary arterial hypertension (PAH) in both patients with and without connective tissue disease, ${ }^{28,29}$ and may have direct activity on SSc patients' fibroblasts. ${ }^{30}$ Recently, selexipag was tested in an RCT of 74 patients with SSc, and no significant differences were identified on Raynaud's phenomenon number or duration of attacks. At baseline, DUs were present in eight and three patients in the placebo and 
selexipag groups, respectively. Only five healed in the placebo group, whereas all three DUs healed in selexipag-treated patients. Of note, the main limitations of this trial were the design of the study, very short titration period, and small number of patients enrolled.

Side effects are possible with both IV and oral administration, including systemic hypotension, headache, dizziness, flushing, gastrointestinal disturbance, jaw pain, and myalgia. Potential ischemic cardiac risk has been linked to prostanoids, probably due to a "stealing" vascular event, which is why this therapy is contraindicated in patients at high cardiovascular risk. ${ }^{31}$

Some patients, particularly those with puffy fingers, may experience the onset of painful digital swelling due to worsening of the edema. There is instead evidence that iloprost is better tolerated in SSc patients in the fibrotic or atrophic stage, where side effects can be managed well by reducing or modulating the infusion rate. Concomitant treatment with nifedipine could contribute to the vasodilating effect, thus fostering the worsening of the edema. Therefore, it is advisable to stop therapy temporarily with nifedipine when iloprost is used. Moreover, a pretreatment approach, eg, an antiemetic drug, may help in reducing or better controlling adverse effects. ${ }^{31}$

\section{Phosphodiesterase type 5 inhibitors}

Phosphodiesterase (PDE) 5 inhibitors inhibit degradation and thus increase the bioavailability of cyclic guanosine monophosphate. This leads to increased endogenous nitric oxide levels, with subsequent vasodilation. ${ }^{32}$ Several PDE5 inhibitors have been proposed in the treatment of SSc-associated vasculopathy, and in the literature three uncontrolled pilot studies have highlighted the beneficial effect of sildenafil on DU healing and its safety. ${ }^{33-35}$

A meta-analysis of three RCTs investigated various selective PDE5 inhibitors:sildenafil $50 \mathrm{mg}$ twice a day, ${ }^{36}$ modified-release sildenafil $100 \mathrm{mg}$ /day increased up to 200 $\mathrm{mg} /$ day, ${ }^{37}$ and tadalafil $20 \mathrm{mg}$ on alternate days. ${ }^{38}$ A total of $85 \mathrm{SSc}$ patients were treated, and the results indicated that PDE5 inhibitors improved DU healing. Although the three RCTs were individually underpowered to detect a statistically significant benefit, the pooled effect showed a definite benefit of PDE5 inhibitors for both DU healing (RR 3.28, $P=0.01$ ) and DU improvement (RR 4.29, $P=0.002$ ). ${ }^{22}$

The SEDUCE study, recently published, was expressly designed to evaluate the effects of sildenafil $(20 \mathrm{mg}$ three times daily for 12 weeks) on DUs in $83 \mathrm{SSc}$ patients. This work revealed that the mean number of DUs per patient was significantly lower in the sildenafil group than the placebo group at weeks $8(1.23 \pm 1.61$ vs $1.79 \pm 2.40, P=0.04)$ and 12 $(0.86 \pm 1.62$ vs $1.51 \pm 2.68, P=0.01)$, resulting from a greater healing rate in the sildenafil group $(P=0.01$ at week 8 and $P=0.03$ at week 12). However, time to DU healing (the primary end point of the study) was not reduced, which the authors attributed to a number of factors, including the unexpectedly high rate of DU healing in the placebo group. ${ }^{39}$

On the basis of all these data, EULAR guidelines state that PDE5 inhibitors should be considered in the treatment of DUs in SSc patients (strength of recommendation: A). ${ }^{26}$ Regarding prevention of new DUs, in the literature there are some positive data on tadalafil, ${ }^{38}$ but this issue needs to be clarified in further studies.

Most common side effects include headache, myalgia, nonpainful erections, allergic reactions, chest pain, palpitations, and facial edema. ${ }^{22}$

\section{Endothelin-receptor antagonists}

Endothelin 1 is a well-known potent vasoconstrictor that also has a marked proliferative effect on smooth-muscle cells and fibroblasts, acting via two receptors $\left(\mathrm{ET}_{\mathrm{A}}\right.$ and $\mathrm{ET}_{\mathrm{B}}$ ). In general, $\mathrm{ET}_{\mathrm{A}}$ and $\mathrm{ET}_{\mathrm{B}}$, found on smooth-muscle cells, promote vasoconstriction and hyperplasia, whereas $\mathrm{ET}_{\mathrm{B}}$, which is also found on endothelial cells, promotes vasodilation. ${ }^{14}$ There is evidence that plasma levels of endothelin 1 in SSc patients with DUs are higher than patients without DUs. ${ }^{40}$ Bosentan is a dual ERA widely used in SSc for the management of both PAH and DUs.

Two high-quality RCTs (RAPIDS-1 and RAPIDS-2) evaluated the effect of bosentan given orally at $62.5 \mathrm{mg}$ twice a day for 4 weeks followed by $125 \mathrm{mg}$ twice a day on DUs in $310 \mathrm{SSc}$ patients.

The RAPIDS-1 study involved 122 patients with active DUs at baseline or at least a history of DUs within the previous 12 months. After 16 weeks of treatment, the bosentan group showed a $48 \%$ reduction in new DUs and a statistically significant improvement in hand function. ${ }^{41}$

The RAPIDS-2 study involved 188 patients with at least one active DU at baseline. After 24 weeks of treatment, there was a $30 \%$ reduction in new DUs in the bosentan group. This effect was most pronounced in SSc patients with multiple (four or more) DUs at baselinecompared with patients with a lower number of DUs at baseline, with no differences between skin subsets. ${ }^{42}$ In both trials, there was thus a significant reduction in the number of new DUs, but bosentan was not able to promote an increase in the healing rate of existing DUs. 
A meta-analysis of these two trials reconfirmed that bosentan was associated with a significant reduction in the mean number of new DUs per patient in the overall trial population $(P=0.004)$ and in patients with baseline DUs $(P=0.005){ }^{22}$ Another recent work confirmed a significant attenuation in hand disability in SSc patients treated with bosentan, thus leading to an improvement in quality of life. $^{43}$

As previously written, neither trial indicated that bosentan was superior to placebo in the healing of active DUs.In the literature, there are several works that instead report a beneficial effect of bosentan onexisting DUs. ${ }^{44-46}$ Further data are needed to settle the question of whether bosentan is useful not only in the prevention but also in the healing of DUs. Multiple studies have finally proven that the efficacy and safety of bosentan is maintained in the long term. ${ }^{44-47}$ On the basis of all these results, EULAR guidelines state that bosentan should be considered for reduction in the number of new DUs in SSc, especially in patients with multiple DUs despite the use of calciumchannel blockers (CCBs), PDE5 inhibitors, or iloprost therapy (strength of recommendation: A). ${ }^{26}$

The aforementioned data refer only to bosentan, but recently data about other endothelin-receptor antagonists (ERAs) were published. Macitentan is a dual ERA licensed for the treatment of PAH, but two RCTs (DUAL-1 and DUAL-2) found no reduction in the number of new DUs from treatment with macitentan. ${ }^{48}$ However, these studies had several limitations, including the relatively short duration of the treatment (16 weeks), the inhomogeneity of the patients enrolled, and use of the old $1980 \mathrm{SSc}$ criteria that were able only to classify patients with long disease duration and/or more severe or advanced disease.

Ambrisentan, also licensed for the treatment of PAH, is a selective $\mathrm{ET}_{\mathrm{A}}$ antagonist, and in two small studies was associated with a reduction in new DUs, ${ }^{49,50}$ but further data are needed to confirm its effectiveness.

The most common adverse effects of ERAs include potential liver injury, and during prescriptions, patients require regular blood monitoring (blood count and liverfunction tests). These drugs are also teratogenic, and contraceptive methods should be used during their administration. It should be noted that hormonal contraceptives may not be reliable if coadministered with bosentan, because it may reduce their efficacy by interference with the cytochrome P450 system. ${ }^{26}$ Another adverse effect, commonly reported, is fluid retention like peripheral edema or pericardial effusion. ${ }^{47}$

\section{Calcium-channel blockers}

CCBs are the first-line choice for Raynaud's phenomenon, but there are very few studies regarding their utility for DUs in SSc. A single double-blind trial compared iloprost IV with nifedipine (starting at $10 \mathrm{mg}$ three times daily and increased to $20 \mathrm{mg}$ three times daily after 4 weeks) in $23 \mathrm{SSc}$ patients. After 16 weeks, both treatments had reduced the frequency, duration, and severity of Raynaud's phenomenon attacks, and iloprost had reduced the mean number of DUs from 3.5 to 0.6 compared with a reduction from 4.3 to 1.4 in the nifedipine group. From this work, it emerges that although nifedipine correlates with a reduction in DUs, the effect is lower than iloprost, and above all it is burdened by a greater number of adverse effects. ${ }^{51}$ To sum up, despite CCBs' first-line role in Raynaud's phenomenon, data are insufficient to suggest a central role for them in the management of DUs.

Common side effects are represented by hypotension, dizziness, flushing, and headaches. ${ }^{26}$

\section{Other pharmacological approaches}

$\mathrm{N}$-acetylcysteine, a precursor of the major antioxidant glutathione, is a substance with a powerful antioxidant and cellular detoxifying action. Administration of $\mathrm{N}$-acetylcysteine IV in SSc patients at a dosage of $15 \mathrm{mg} / \mathrm{kg} / \mathrm{h}$ for 5 hours every 2 weeksd, in addition to a decrease of frequency and severity of Raynaud's phenomenon attacks, resulted in a significant reduction in DUs/patient/year, proving also to be an effective and well-tolerated treatment in the long term. ${ }^{52,53}$

An RCT on $84 \mathrm{SSc}$ patients reported that treatment with atorvastatin $40 \mathrm{mg} /$ day for 4 months was associated with a reduction in the overall number of DUs, as was the mean number of new DUs per patient in the treatment group. $^{54}$

It should be emphasized that the results reported by the two aforementioned drugs derive from a small number of studies on a limited number of patients. Given the need for more evidence on the potential benefit of these two drugs, their use for the treatment of SSc DUs should be carefully weighed by physicians.

Although many doctors prescribe antiplatelet therapy for DUs, there is a lack of scientific evidence to support this kind of intervention. An RCT on SSc patients receiving dual-antiplatelet therapy (aspirin and dipyridamole) showed no difference in new DUs over 1-2 years of 
treatment. $^{55}$ It was even hypothesized that clopidogrel treatment may be associated with the development of new DUs. ${ }^{56}$ Moreover, the fact that many SSc patients have gastrointestinal involvement with a propensity to bleeding should be taken into account before administering antiplatelets, many of which can induce bleeding.

\section{Combination therapy}

Although there are no RCTs addressing vasoactive therapies in combination for SSc DUs, in clinical practice this type of association is often used when the situation is particularly severe. Also, the EULAR guidelines state that in severe cases, iloprost IV can be used in combination with oral vasodilators, properly taking into account the increased risk of side effects. ${ }^{26}$

It has been demonstrated that the association of iloprost with bosentan determines a progressive and lasting increase in fingertip blood perfusion, as well as nail-fold capillary numbers. ${ }^{57,58}$ A recent retrospective observational study on 34 SSc patients with at least one active DU refractory to iloprost evaluated the effect of additional bosentan therapy. After 6 months, no new DUs had been recorded, and of 58 DUs at baseline $58 \%$ had completely healed, whereas $25 \%$ were partially healed. By dividing patients according to the degree of fibrosis, it was seen that the group with mild fibrosis (finger Rodnan skin score $\leq 1)$ showed a significantly higher rate of completely healed DUs than patients with more severe fibrosis. ${ }^{59}$

The SEDUCE study reported that the time to DUs healing was significantly shorter in the sildenafil + bosentan subgroup than in a placebo + bosentan subgroup. ${ }^{39}$ Moreover, combination therapies of sildenafil with other vasoactive treatments like prostanoids or CCBs showed good safety and tolerability. ${ }^{35}$

In summary, as recommended also by a United Kingdom best-practice consensus, when DUs are troublesome but outpatient management is appropriate, vasodilator therapy should be optimized by increasing the current dose or adding an alternative vasodilator. Most severe DUs require hospitalization, and continuous or extended courses of iloprost IV should be considered in refractory cases. In patients with nonhealing refractory DUs, after evaluation of the risk:benefit ratio, the combination of iloprost IV with a PDE5 inhibitor and bosentan may be beneficial. $^{9}$

\section{Topical treatment}

Despite local treatment for DUs in SSc patients being necessary as an adjunct, no trials or other reports are available for topical wound dressing for DUs in SSc patients. An adaptation of the generally accepted approaches for the management of the wounds in SSc patients is thus necessary.

In this framework, application of the principles of wound-bed preparation is mandatory. ${ }^{60}$ In particular, the TIME (issue, inflammation/infection, moisture imbalance, epithelial edge advancement), approach ${ }^{61}$ should be promoted and adapted for SSc patients. Application of TIME principles to SSc DUs should be adapted to comply with the peculiar characteristics of SSc patients.

The management of wound-bed tissue involves assessment of the presence of exudate, biofilm, slough, and necrotic tissue.

The first phase of wound-bed preparation is wound cleansing. This preparatory phase is the first step to remove debris, slough, bacteria, and other contaminants, including previous wound dressing. Due to the lack of studies on wound cleansing in SSc, we recommend the same procedures commonly applied in other skin ulcers, including the use of sterile saline solution, sterile water, and in some cases also tap water, for irrigation of the DU. ${ }^{62}$ Other procedures may include antiseptic solutions, such as sodium hypochlorite $0.5 \%$, or other irrigation solutions like polyhexanide with betaine. ${ }^{63}$ In any case, we suggest the use of povidone-iodine only in the case of severely contaminated lesions.

In order to promote wound healing, nonviable tissue should be removed by debridement. In SSc patients, different debridement approaches may be applied, but there are no accepted protocols or guidelines to follow.

Surgical debridement is an invasive method that use a curette or a scalpel. This approach is effective for removal of nonviable tissue, and in routine clinical practice represents the gold standard for debridement ${ }^{62}$ and is necessary to reduce bacterial contamination and local infection. ${ }^{64}$ This approach requires a skilled practitioner and efficacious local anesthesia and general analgesia.

Local anesthetic, such as the application of topical lidocaine or a fixed combination of lidocaine-prilocaine, may be useful to reduce pain during the procedure and allowing a safe debridement procedure. ${ }^{13,65}$ When local lidocaine is not sufficient, in the case of persistent pain, an administration of 
local morphine or the addition of oral morphine may improve pain management during DU debridement. ${ }^{13}$

Where surgical debridement is not accepted or tolerated by the patient, autolytic debridement should be proposed. This method promotes the degradation of necrotic tissue and slough using dressing like hydrocolloid, alginate, and hydrogels. In selected cases of DUs with thick necrosis, the application of collagenase-based ointments may promote the removal of necrotic tissue in ischemic DUs. ${ }^{66}$

Recently, the use of ultrasonic-assisted wound debridement has been proposed for SSc DUs. This procedure uses low-frequency ultrasound waves, is considered less traumatic and painful thanstandard debridement, and may allow more effective removal of nonviable tissue from the lesion. ${ }^{67} \mathrm{~A}$ recent paper reported that ultrasoundassisted wound debridement reduced pain, necessity of antimicrobial therapy, and healing time in SSc patients. ${ }^{68}$

The presence of infection should be carefully investigated during evaluation of the patient with DUs during SSc. Actually, the presence of infection is associated with a higher risk of local complications and reduced healing of DUs. ${ }^{69}$ Moreover, the presence of infection in SSc DUs may evolve toward osteomyelitis, leading to bone necrosis and destruction. ${ }^{70}$ Although Staphylococcus aureus seems to be the main agent responsible for DU infections, a high percentage of SSc patients present infections due to fecal pathogens, such as Escherichia coli and Enterococcus faecalis, suggesting a possible role of contamination during handwashing and home medications. ${ }^{10}$ Infections should be confirmed by clinical examination of the wound and always confirmed by a deep wound swab, ${ }^{71}$ and treated with local antiseptics and if needed systemic antibiotics. Local antibiotics may be of limited use in SSc patients, as the majority of them may act as potent sensitizers. Moreover, the efficacy of these solutions in SSc DUs is still under review. ${ }^{66}$

The moisture balance is crucial in the management of wounds, and in SSc patients' DUs may improve wound healing, promoting granulation-tissue formation and managing exudate, preventing maceration of the surrounding skin. To our knowledge, no advanced dressings have been investigated yet for the management of DUs in SSc patients, and thus the general principles for wound management may be applied.

An optimal dressing should be chosen based on the characteristics of DUs and be easy to apply and remove from the wound. In the last few years, an important step forward was made by the development of protease-modulating dressings that have a double action: they are able to absorb excess wound exudate and can reduce metalloproteinase levels in exudate that may be responsible for reduced wound healing. ${ }^{72}$

Although no literature data are available for the management of SSc DUs, topical hydrocolloid dressings have been suggested as the treatment of choice., ${ }^{4,66}$ In our experience, the management of moisture imbalance obtainable with these medications is not always satisfying, and due to the high risk of infections in SSc DUs, the use of dressings with antimicrobial activity should be preferable. In particular, silver-containing dressings may help in controlling local infections, reducing the need for systemic and topical antibiotics. ${ }^{73}$ However, some patients may present discomfort and pain when a silver-containing dressing is applied. ${ }^{74}$ For patients in which silver-containing dressing is not indicated, dialkylcarbomoyl chloridecoated dressings may also be used for the management of infections and moisture imbalance in wounds. ${ }^{75}$ These high-technology dressings are active also against methicillin-resistant S.aureus (MRSA) and Pseudomonas aerugi$n o s a$, two of the most difficult-to-treat bacteria. ${ }^{76}$

Dressing changes should occur daily, on alternate days, or twice a week according to the size/characteristics of the lesions and the type of dressing applied.

Evaluation of wound edges should be performed regularly, as progressive wound contraction confirms that the current treatment is effective. Together with wound edges, surrounding skin should be carefully examined to identify dry or macerated skin, in order to modify ulcer management and dressings accordingly. ${ }^{62}$

For nonhealing DUs, in addition to correct systemic and topical management, some innovative approaches may be proposed. Digital sympathectomy may be useful to control Raynaud's phenomenon, increase blood flow, and improvhealing, ${ }^{77-79}$ and may also be used in earlier phases to decrease DU-related pain. ${ }^{79}$ Also, a cellular therapy using autologous adipose tissue-derived cells has been suggested as a possible treatment for chronic ulcers, ${ }^{80,81}$ and may improve local vascularization and promote healing. Additionally, the use of allogenic skin grafting can promote healing and rapidly reduce the pain of DUs. ${ }^{82}$

\section{Conclusion}

The management of DUs in SSc patients is complex and requires a combination of pharmacological and nonpharmacological approaches. Interestingly, while different drug combinations have been tested and proposed for facilitating wound healing, no RCTs or observational studies have 
investigated the possible adjunctive effect of topical wound management or pharmacological interventions. This may explain the difficulty in conducting RCTs demonstrating efficacy of drugs on DU healing,as the topical approach is still not clearly defined or standardized.

\section{Ethics statement}

All patients gave us their written informed consent to allow us to publish their photos.

\section{Disclosure}

The authors report no conflicts of interest in this work.

\section{References}

1. Klein-Weigel P, Opitz C, Riemekasten G. Systemic sclerosis - a systematic overview: part 1 - disease characteristics and classification, pathophysiologic concepts, and recommendations for diagnosis and surveillance. Vasa. 2011;40:6-19. doi:10.1024/0301-1526/a000065

2. Walker UA, Tyndall A, Czirják L, et al. Clinical risk assessment of organ manifestations in systemic sclerosis: a report from the EULAR scleroderma trials and research group database. Ann Rheum Dis. 2007;66:754-763. doi:10.1136/ard.2006.062901

3. Cutolo M, Sulli A, Smith V. Assessing microvascular changes in systemic sclerosis diagnosis and management. Nat Rev Rheumatol. 2010;6:578-587. doi:10.1038/nrrheum.2010.104

4. Chung L, Fiorentino D. Digital ulcers in patients with systemic sclerosis. Autoimmun Rev. 2006;5:125-128. doi:10.1016/j.autrev.2005.08.004

5. Herrick AL. Recent advances in the pathogenesis and management of Raynaud's phenomenon and digital ulcers. Curr Opin Rheumatol. 2016;28:577-585. doi:10.1097/BOR.0000000000000332

6. Wigley FM, Flavahan NA. Raynaud's phenomenon. Campion EW, ed. $N$ Engl J Med. 2016;375:556-565. doi:10.1056/NEJMra1507638

7. Morrisroe K, Frech T, Schniering J, Maurer B, Nikpour M. Systemic sclerosis: the need for structured care. Best Pract Res Clin Rheumatol. 2016;30:3-21. doi:10.1016/j.berh.2016.04.004

8. Caramaschi P, Martinelli N, Volpe A, et al. A score of risk factors associated with ischemic digital ulcers in patients affected by systemic sclerosis treated with iloprost. Clin Rheumatol. 2009;28:807813. doi:10.1007/s10067-009-1155-6

9. Hughes M, Ong VH, Anderson ME, et al. Consensus best practice pathway of the UK scleroderma study group: digital vasculopathy in systemic sclerosis. Rheumatology (Oxford). 2015;54:2015-2024. doi:10.1093/rheumatology/kev201

10. Giuggioli D, Manfredi A, Colaci M, Lumetti F, Ferri C. Scleroderma digital ulcers complicated by infection with fecal pathogens. Arthritis Care Res (Hoboken). 2012;64:295-297. doi:10.1002/acr.20673

11. Cooke JP, Marshall JM. Mechanisms of Raynaud's disease. Vasc Med. 2005;10:293-307. doi:10.1191/1358863x05vm639ra

12. Malenfant D, Catton M, Pope JE. The efficacy of complementary and alternative medicine in the treatment of Raynaud's phenomenon: a literature review and meta-analysis. Rheumatology. 2009;48:791795. doi:10.1093/rheumatology/kep039

13. Giuggioli D, Manfredi A, Vacchi C, Sebastiani M, Spinella A, Ferri C. Procedural pain management in the treatment of scleroderma digital ulcers. Clin Exp Rheumatol. 2015;33:5-10.

14. Hughes M, Herrick AL. Digital ulcers in systemic sclerosis. Rheumatology (Oxford). 2017;56:14-25. doi:10.1093/rheumatology/ kew047
15. Pellar RE, Pope JE. Evidence-based management of systemic sclerosis: navigating recommendations and guidelines. Semin Arthritis Rheum. 2017;46:767-774. doi:10.1016/j.semarthrit.2016.12.003

16. Hoes JN, Jacobs JWG, Boers M, et al. EULAR evidence-based recommendations on the management of systemic glucocorticoid therapy in rheumatic diseases. Ann Rheum Dis. 2007;66:1560-1567. doi:10.1136/ard.2007.072157

17. Au K, Mayes MD, Maranian P, et al. Course of dermal ulcers and musculoskeletal involvement in systemic sclerosis patients in the scleroderma lung study. Arthritis Care Res (Hoboken). 2010;62:1772-1778. doi:10.1002/acr.20320

18. Wigley FM, Seibold JR, Wise RA, McCloskey DA, Dole WP. Intravenous iloprost treatment of Raynaud's phenomenon and ischemic ulcers secondary to systemic sclerosis. J Rheumatol. 1992;19:1407-1414.

19. Wigley FM, Wise RA, Seibold JR, et al. Intravenous iloprost infusion in patients with Raynaud phenomenon secondary to systemic sclerosis. A multicenter, placebo-controlled, double-blind study. Ann Intern Med. 1994;120:199-206.

20. Seibold JR, Wigley FM, Schiopu E, et al. Digital ulcers in ssc treated with oral treprostinil: a randomized, double-blind, placebo-controlled study with open-label follow-up. J Scleroderma Relat Disord. 2017;2:42-49. doi:10.5301/jsrd.5000232

21. Shah AA, Schiopu E, Chatterjee S, et al. The recurrence of digital ulcers in patients with systemic sclerosis after discontinuation of oral treprostinil. $J$ Rheumatol. 2016;43:1665-1671. doi:10.3899/ jrheum. 151437

22. Tingey T, Shu J, Smuczek J, Pope J. Meta-analysis of healing and prevention of digital ulcers in systemic sclerosis. Arthritis Care Res (Hoboken). 2013;65:1460-1471. doi:10.1002/acr.22018

23. Colaci M, Lumetti F, Giuggioli D, et al. Long-term treatment of scleroderma-related digital ulcers with iloprost: a cohort study. Clin Exp Rheumatol. 2017;35(Suppl 1):179-183.

24. Grant SM, Goa KL. Iloprost. Drugs. 1992;43:889-924. doi:10.2165/ 00003495-199243060-00008

25. Casigliani Rabl S, Della Rossa A, Pepe P, et al. Long-term cyclic intravenous iloprost in systemic sclerosis: clinical experience from a single center. Reumatismo. 2012;64:158-165. doi:10.4081/reumatismo.2012.158

26. Kowal-Bielecka O, Fransen J, Avouac J, et al. Update of EULAR recommendations for the treatment of systemic sclerosis. Ann Rheum Dis. 2017;76:1327-1339. doi:10.1136/annrheumdis-2016-209909

27. Kawald A, Burmester GR, Huscher D, Sunderkotter C, Riemekasten G. Low versus high-dose iloprost therapy over 21 days in patients with secondary Raynaud's phenomenon and systemic sclerosis: a randomized, open, single-center study. J Rheumatol. 2008;35:1830-1837.

28. Sitbon O, Channick R, Chin KM, et al. Selexipag for the treatment of pulmonary arterial hypertension. N Engl J Med. 2015;373:25222533. doi:10.1056/NEJMoa1503184

29. Gaine S, Chin K, Coghlan G, et al. Selexipag for the treatment of connective tissue disease-associated pulmonary arterial hypertension. Eur Respir J. 2017;50:1602493.

30. Cutolo M, Ruaro B, Montagna P, et al. Effects of selexipag and its active metabolite in contrasting the profibrotic myofibroblast activity in cultured scleroderma skin fibroblasts. Arthritis Res Ther. 2018;20:77. doi:10.1186/s13075-018-1577-0

31. Bellando-Randone S, Bruni C, Lepri G, et al. The safety of iloprost in systemic sclerosis in a real-life experience. Clin Rheumatol. 2018;37:1249-1255. doi:10.1007/s10067-018-4043-0

32. Roustit M, Hellmann M, Cracowski C, Blaise S, Cracowski JL. Sildenafil increases digital skin blood flow during all phases of local cooling in primary Raynaud's phenomenon. Clin Pharmacol Ther. 2012;91:813-819. doi:10.1038/clpt.2011.302

33. Brueckner CS, Becker MO, Kroencke T, et al. Effect of sildenafil on digital ulcers in systemic sclerosis: analysis from a single centre pilot study. Ann Rheum Dis. 2010;69:1475-1478. doi:10.1136/ $\operatorname{ard} .2009 .116475$ 
34. Kumar U, Sankalp G, Gokhle SS, Sreenivas V, Kaur S, Misra D. Prospective, open-label, uncontrolled pilot study to study safety and efficacy of sildenafil in systemic sclerosis-related pulmonary artery hypertension and cutaneous vascular complications. Rheumatol Int. 2013;33:1047-1052. doi:10.1007/s00296-012-2466-5

35. Della Rossa A, Doveri M, D'Ascanio A, et al. Oral sildenafil in skin ulcers secondary to systemic sclerosis. Scand $J$ Rheumatol. 2011;40:323-325. doi:10.3109/03009742.2011.569755

36. Fries R, Shariat K, von Wilmowsky H, Böhm M. Sildenafil in the treatment of Raynaud's phenomenon resistant to vasodilatory therapy Circulation. 2005;112:2980-2985. doi:10.1161/CIRCULATIONAHA. 104.523324

37. Herrick AL, van Den Hoogen F, Gabrielli A, et al. Modified-release sildenafil reduces Raynaud's phenomenon attack frequency in limited cutaneous systemic sclerosis. Arthritis Rheum. 2011;63:775-782. doi:10.1002/art.30195

38. Shenoy PD, Kumar S, Jha LK, et al. Efficacy of tadalafil in secondary Raynaud's phenomenon resistant to vasodilator therapy: a doubleblind randomized cross-over trial. Rheumatology. 2010;49:24202428. doi:10.1093/rheumatology/keq291

39. Hachulla E, Hatron P-Y, Carpentier P, et al. Efficacy of sildenafil on ischaemic digital ulcer healing in systemic sclerosis: the placebocontrolled SEDUCE study. Ann Rheum Dis. 2016;75:1009-1015. doi:10.1136/annrheumdis-2014-207001

40. Aghaei M, Gharibdost F, Zayeni H, et al. Endothelin-1 in systemic sclerosis. Indian Dermatol Online J. 2012;3:14-16. doi:10.4103/22295178.93484

41. Korn JH, Mayes M, Matucci Cerinic M, et al. Digital ulcers in systemic sclerosis: prevention by treatment with bosentan, an oral endothelin receptor antagonist. Arthritis Rheum. 2004;50:3985-3993. doi:10.1002/art.20676

42. Matucci-Cerinic M, Denton CP, Furst DE, et al. Bosentan treatment of digital ulcers related to systemic sclerosis: results from the RAPIDS-2 randomised, double-blind, placebo-controlled trial. Ann Rheum Dis. 2011;70:32-38. doi:10.1136/ard.2010.130658

43. Mouthon L, Carpentier PH, Lok C, et al. Controlling the digital ulcerative disease in systemic sclerosis is associated with improved hand function. Semin Arthritis Rheum. 2017;46:759-766. doi:10.1016/j.semarthrit.2017.01.001

44. Garcia de la Pena-Lefebvre P, Rodriguez RS, Valero EM, et al. Longterm experience of bosentan for treating ulcers and healed ulcers in systemic sclerosis patients. Rheumatology (Oxford). 2008;47:464-466.

45. Roman Ivorra JA, Simeon CP, Alegre Sancho JJ, et al. Bosentan in clinical practice for treating digital and other ischemic ulcers in Spanish patients with systemic sclerosis: IBER-DU cohort study. $J$ Rheumatol. 2011;38:1631-1635. doi:10.3899/jrheum.101266

46. Tsifetaki N, Botzoris V, Alamanos Y, Argyriou E, Zioga A, Drosos AA. Bosentan for digital ulcers in patients with systemic sclerosis: a prospective 3-year followup study. J Rheumatol. 2009;36:1550-1552. doi:10.3899/jrheum.080992

47. Hamaguchi Y, Sumida T, Kawaguchi Y, et al. Safety and tolerability of bosentan for digital ulcers in Japanese patients with systemic sclerosis: prospective, multicenter, open-label study. $J$ Dermatol. 2017;44:13-17. doi:10.1111/1346-8138.13497

48. Khanna D, Denton CP, Merkel PA, et al. Effect of macitentan on the development of new ischemic digital ulcers in patients with systemic sclerosis: DUAL-1 and DUAL-2 randomized clinical trials. JAMA. 2016;315:1975-1988. doi:10.1001/jama.2016.5258

49. Parisi S, Peroni CL, Laganà $\mathrm{A}$, et al. Efficacy of ambrisentan in the treatment of digital ulcers in patients with systemic sclerosis: a preliminary study. Rheumatology (Oxford). 2013;52:1142-1144. doi:10.1093/rheumatology/ket019

50. Chung L, Ball K, Yaqub A, Lingala B, Fiorentino D. Effect of the endothelin type A-selective endothelin receptor antagonist ambrisentan on digital ulcers in patients with systemic sclerosis: results of a prospective pilot study. $J \mathrm{Am}$ Acad Dermatol. 2014;71:400-401. doi:10.1016/j.jaad.2014.04.028
51. Rademaker M, Cooke ED, Almond NE, et al. Comparison of intravenous infusions of iloprost and oral nifedipine in treatment of Raynaud's phenomenon in patients with systemic sclerosis: a double blind randomised study. BMJ. 1989;298:561-564.

52. Sambo P, Amico D, Giacomelli R, et al. Intravenous N-acetylcysteine for treatment of Raynaud's phenomenon secondary to systemic sclerosis: a pilot study. J Rheumatol. 2001;28:2257-2262.

53. Rosato E, Borghese F, Pisarri S, Salsano F. The treatment with N-acetylcysteine of Raynaud's phenomenon and ischemic ulcers therapy in sclerodermic patients: a prospective observational study of 50 patients. Clin Rheumatol. 2009;28:1379-1384. doi:10.1007/s10067-009-1251-7

54. Abou-Raya A, Abou-Raya S, Helmii M. Statins: potentially useful in therapy of systemic sclerosis-related Raynaud's phenomenon and digital ulcers. J Rheumatol. 2008;35:1801-1808.

55. Beckett VL, Conn DL, Fuster V, et al. Trial of platelet-inhibiting drug in scleroderma. Double-blind study with dipyridamole and aspirin. Arthritis Rheum. 1984;27:1137-1143.

56. Ntelis K, Gkizas V, Filippopoulou A, et al. Clopidogrel treatment may associate with worsening of endothelial function and development of new digital ulcers in patients with systemic sclerosis: results from an open label, proof of concept study. BMC Musculoskelet Disord. 2016;17:213.

57. Cutolo M, Ruaro B, Pizzorni C, et al. Longterm treatment with endothelin receptor antagonist bosentan and iloprost improves fingertip blood perfusion in systemic sclerosis. J Rheumatol. 2014;41:881886. doi: $10.3899 /$ jrheum. 131284

58. Cestelli V, Manfredi A, Sebastiani M, et al. Effect of treatment with iloprost with or without bosentan on nailfold videocapillaroscopic alterations in patients with systemic sclerosis. Mod Rheumatol. 2017;27:110-114. doi:10.1080/14397595.2016.1192761

59. De Cata A, Inglese M, Molinaro F, et al. Digital ulcers in scleroderma patients: A retrospective observational study. Int J Immunopathol Pharmacol. 2016;29:180-187. doi:10.1177/0394632015606846

60. Schultz GS, Sibbald RG, Falanga V, et al. Wound bed preparation: a systematic approach to wound management. Wound Repair Regen. 2003;11(Suppl 1):S1-S28.

61. Schultz GS, Barillo DJ, Mozingo DW, Chin GA. Wound bed advisory board members. Wound bed preparation and a brief history of TIME. Int Wound J. 2004;1:19-32. doi:10.1111/j.1742-481x.2004.00008.x

62. Harries RL, Bosanquet DC, Harding KG. Wound bed preparation: TIME for an update. Int Wound J. 2016;13:8-14. doi:10.1111/iwj.12662

63. Bellingeri A, Falciani F, Traspedini P, et al. Effect of a wound cleansing solution on wound bed preparation and inflammation in chronic wounds: a single-blind RCT. J Wound Care. 2016;25:160, 162-166, 168. doi:10.12968/jowc.2016.25.3.160

64. Amanzi L, Braschi F, Fiori G, et al. Digital ulcers in scleroderma: staging, characteristics and sub-setting through observation of 1614 digital lesions. Rheumatology (Oxford). 2010;49:1374-1382. doi:10.1093/rheumatology/keq097

65. Braschi F, Bartoli F, Bruni C, et al. Lidocaine controls pain and allows safe wound bed preparation and debridement of digital ulcers in systemic sclerosis: a retrospective study. Clin Rheumatol. 2017;36:209-212. doi:10.1007/s10067-016-3414-7

66. Lebedoff N, Frech TM, Shanmugam VK, et al. Review of local wound management for scleroderma-associated digital ulcers. $J$ Scleroderma Relat Disord. 2018;3:66-70. doi:10.5301/jsrd.5000268

67. Kavros SJ, Miller JL, Hanna SW. Treatment of ischemic wounds with noncontact, low-frequency ultrasound: the Mayo clinic experience, 2004-2006. Adv Skin Wound Care. 2007;20:221-226. doi:10.1097/ 01.ASW.0000266660.88900.38

68. Marcoccia A, Salvucci C, D'Alesio T, et al. Ultrasonic-assisted wound debridement for scleroderma digital ulcers. Italy $J$ Wound Care. 2018. doi:10.4081/ijwc.2017.11

69. Alivernini S, De Santis M, Tolusso B, et al. Skin ulcers in systemic sclerosis: determinants of presence and predictive factors of healing. $J$ Am Acad Dermatol. 2009;60:426-435. doi:10.1016/j.jaad.2008.11.025 
70. Giuggioli D, Manfredi A, Colaci M, Lumetti F, Ferri C. Osteomyelitis complicating scleroderma digital ulcers. Clin Rheumatol. 2013;32:623-627. doi:10.1007/s10067-012-2161-7

71. Giuggioli D, Manfredi A, Lumetti F, Colaci M, Ferri C. Scleroderma skin ulcers definition, classification and treatment strategies our experience and review of the literature. Autoimmun Rev. 2018;17:155-164. doi:10.1016/j.autrev.2017.11.020

72. Lazaro JL, Izzo V, Meaume S, Davies AH, Lobmann R, Uccioli L. Elevated levels of matrix metalloproteinases and chronic wound healing: an updated review of clinical evidence. $J$ Wound Care. 2016;25:277-287. doi:10.12968/jowc.2016.25.5.277

73. Karinja SJ, Spector JA. Treatment of infected wounds in the age of antimicrobial resistance. Plast Reconstr Surg. 2018;142:1082-1092. doi:10.1097/PRS.0000000000004799

74. Rodriguez-Arguello J, Lienhard K, Patel P, et al. A scoping review of the use of silver-impregnated dressings for the treatment of chronic wounds. Ostomy Wound Manage. 2018;64:14-31.

75. Totty JP, Bua N, Smith GE, et al. Dialkylcarbamoyl chloride (DACC)coated dressings in the management and prevention of wound infection: a systematic review. J Wound Care. 2017;26:107-114.

76. Cooper R, Jenkins L. Binding of two bacterial biofilms to dialkyl carbamoyl chloride (DACC)-coated dressings in vitro. $J$ Wound Care. 2016;25:76-82. doi:10.12968/jowc.2016.25.2.76
77. Chiou G, Crowe C, Suarez P, Chung L, Curtin C, Chang J. Digital sympathectomy in patients with scleroderma: an overview of the practice and referral patterns and perceptions of rheumatologists. Ann Plast Surg. 2015;75:637-643. doi:10.1097/SAP.0000000000000614

78. Wasserman A, Brahn E. Systemic sclerosis: bilateral improvement of Raynaud's phenomenon with unilateral digital sympathectomy. Semin Arthritis Rheum. 2010;40:137-146. doi:10.1016/j.semarthrit.2009.08.002

79. Momeni A, Sorice SC, Valenzuela A, Fiorentino DF, Chung L, Chang J. Surgical treatment of systemic sclerosis-is it justified to offer peripheral sympathectomy earlier in the disease process? Microsurgery. 2015;35:441-446. doi:10.1002/micr.22379

80. Del Papa N, Di Luca G, Sambataro D, et al. Regional implantation of autologous adipose tissue-derived cells induces a prompt healing of longlasting indolent digital ulcers in patients with systemic sclerosis. Cell Transplant. 2015;24:2297-2305. doi:10.3727/096368914X685636

81. Del BM, Pozzi MR, Rovati L, Mazzola I, Erba G, Bonomi S. Autologous fat grafting for scleroderma-induced digital ulcers. An effective technique in patients with systemic sclerosis. Handchir Mikrochir Plast Chir. 2014;46:242-247. doi:10.1055/s-0034-1376970

82. Barsotti S, Mattaliano V, d' Ascanio A, et al. Systemic sclerosis chronic ulcers: preliminary results of treatment with allogenic skin grafting in a cohort of Italian patients. Int Wound J. 2015. doi:10.1111/iwj.12424
Chronic Wound Care Management and Research

\section{Publish your work in this journal}

Chronic Wound Care Management and Research is an international, peer reviewed, open access, online journal publishing original research, reviews, editorials, and commentaries on the causes and management of chronic wounds and the major issues related to chronic wound management. Topics also include chronic wounds as comorbidities to

\section{Dovepress}

other conditions, patient adherence to therapy, and the economic burden of chronic wounds. The manuscript management system is completely online and includes a very quick and fair peer review system, which is all easy to use. Visit http://www.dovepress.com/ testimonials.php to read real quotes from published authors. 